\title{
A Panel Data Analysis on the Relationship Between Real Estate Value And GDP
}

\author{
1. Huachao Qian \\ College of civil engineering, Nanjing Forestry \\ University \\ 13776625395@163.com \\ 2. Jian Chen \\ College of civil engineering, Nanjing Forestry \\ University.
}

\author{
3. Qi Wang \\ College of civil engineering, Nanjing Forestry \\ University, \\ 593522491@qq.com \\ 4. Chen Liu \\ College of civil engineering, Nanjing Forestry \\ University \\ 983460635@qq.com
}

\begin{abstract}
In this paper, we use the panel data over the period of 2002 - 2012 from 29 provinces in China to test the impacts of real estate value on the GDP. The result shows that the real estate value has a positive effect on GDP, but the output value has a biphasic effect on GDP and there are strong regional differences in the strength of influence. And the authors put forward policy recommendations according to the empirical results.
\end{abstract}

Keywords- Data Analysis; GDP; Real Estate Value

\section{INTRODUCTION}

Real estate as one of the pillar industries of the national economy has made a great contribution on China's economic growth. Firstly, the real estate industry provides physical space conditions for national economic sectors and it is an important part of fixed assets. Secondly, the real estate industry can promote and lead the common development of the telated industries of the national economy. On the other hand, it can optimize the industrial structure and improve agglomeration benefit. Finally, real estate is an important source of funds for construction of the national economy. We can say that the real estate industry is the most important industry of PNB and this this determines the close relationship between the amount of investment and GDP. In recent years, China's annual GDP growth rates has been driven by real estate accounts for at least two percentage points. In the year of 2005 , the investment in real estate is almost the equivalent of 13 percent of gross domestic product, and the real estate has become a pillar industry of China. On april 26, 2007, "China Real Estate Blue Book" published and it showed that 2006 China's real estate investment for 1.94 trillion yuan, accounting for 17.6 percent of the total that year the whole society fixed asset investment and the investment growth rate is $21.8 \%$, accounting for $9.26 \%$ of GDP, while the internationally recognized real estate value to GDP ratio is reasonable for $5 \%$. This paper makes an empirical Study on the relationship between real estate value and GDP on the base of the panel data analysis from the year 2002 to 2012 .

\section{Mechanism Of the Real Estate Value to GDP}

Real estate has a long industrial chain, the leading role and other characteristics. Its movements will have a greater shock on a number of related industries and has a impact on macroeconomic stability and harmonious development. Driving effect of the real estate industry will have an impact on GDP both from the direct and indirect.

A. Direct Influence: (1) The increase of real estate revenue will cause the increase of GDP. (2) Developers' faster flow of capital and promote upstream investment and thereby increasing GDP. (3) The increase income of dozens of downstream industries closely associated with the real estate industry make the GDP increase.

B. Indirect Effects: (1) The GDP will increase since banks provide a large number of loans for real estate developers. (2) The revenue of the government will increase with the increase of the tax, and it finally can increase the GDP. (3) Asset price inflation has brought widespread asset appreciation of the society, the aggregate demand and GDP will increase through the wealth effect on the economy of a strong short-term effect..

The results are quite different since the GDP under the direct and indirect effects of the real estate value. Therefore, the present study aims to answer two questions: (1) What the impact will real estate value cause on GDP? and whether there are regional differences between them? (2) The extent of the real estate value to GDP? Only through the collection of both data, mathematical model to analysis the relationship between the numbers can we obtain a relatively rigorous conclusions.

\section{INDEX SELECTION AND MODEL BUILDING}

\section{A. Index Selection}

In this paper,we select the following index: (1) Real estate sales, we use commercial housing sales area of application (CHA) to represent the real estate sales. (2) commercial housing price (AHP) (3) GDP. As Shanghai and Tibet statistical data are missing and affordable housing system in the actual situation, the data object to 29 provinces, municipalities and autonomous regions of 
the real estate market development sample data span the period 2002-2012, a total sample of 319. Data comes from "China Statistical Yearbook."

\section{B. Model development}

\section{1) Unit root test}

At the $1 \%$ significance level, commercial housing prices, the supply of commercial housing area and GDP are non- stationary time series data.There are unit root, so the order of the original sequence of a stationary test results show the commercial housing prices, supply area and the GDP exist an order one, consistent cointegration relationship between variables basis, and the test results are shown in Table 1 .

TABLE 1 THREE VARIABLE ORDER 1 UNIT ROOT TEST RESULTS

\begin{tabular}{|l|l|l|l|l|l|l|}
\hline \multirow{2}{*}{$\begin{array}{l}\text { Test } \\
\text { methods }\end{array}$} & \multicolumn{2}{|c|}{ GDP } & \multicolumn{2}{l|}{$\begin{array}{l}\text { Commercial } \\
\text { price }\end{array}$} & housing sales & \multicolumn{2}{c|}{ Commercial housing sales area } \\
\cline { 2 - 7 } & Statistics & P-statistics & Statistics & P-statistics & Statistics & P-statistics \\
\hline LLC & -7.83189 & $0.0000^{* *}$ & -9.7076 & 0.0000 & -18.5723 & 0.0000 \\
\hline IPS & -4.70868 & 0.0000 & -4.3723 & 0.0000 & -10.9171 & 0.0000 \\
\hline ADF & 115.9576 & 0.0000 & 105.892 & 0.0000 & 188.0624 & 0.0000 \\
\hline PP & 227.636 & 0.0000 & 169.3424 & 0.0000 & 221.3336 & 0.0000 \\
\hline
\end{tabular}

\section{2) Cointegration test}

By Cointegration test, indicators basically conform to several methods, such as Panel rho、 Panel V test, data basically conform to the cointegration test, we can conclusion that the three have a long-term equilibrium relationship. Test indicators are shown in table 2.

TABLE 2 THREE VARIABLES COINTEGRATION TEST

\begin{tabular}{|l|l|l|l|l|l|}
\hline Test methods & Statistics & $\begin{array}{l}\text { P-statisti } \\
\text { cs }\end{array}$ & Test methods & Statistics & P-statistics \\
\hline Panel v-Statistic & 1.537115 & 0.0652 & Group rho-Statistic & 3.714748 & 0.0276 \\
\hline Panel rho-Statistic & 0.948670 & 0.70616 & Group PP-Statistic & -2.917157 & 0.00008 \\
\hline & & & & & 0.03176 \\
Panel PP-Statistic & -3.442759 & 0.0000 & Group ADF-Statistic & 1.617883 & \\
\hline
\end{tabular}

3) The choice of panel model

In order to define the variables form, we build the influence of random effect model and fixed effect model.
Then we set out to Hausman test and likelihood ratio test (LR) to judge the influence form. The test results are shown in Table 3.

TABLE 3 HAUSMAN\&LR TEST RESULT

\begin{tabular}{|l|l|l|l|l|}
\hline & Type & chi-sq.statistic & chi-sq.df & P-statistic \\
\hline Hauseman test & Cross-section random effects & 16.02664 & 1.6 & 0.0344 \\
\hline \multirow{2}{*}{ LR test } & Cross-section chi-sq. & 137.37745 & 22.4 & 0.0000 \\
\cline { 2 - 5 } & Cross-section F & 6.1276072 & $(22.4,182.4)$ & 0.0000 \\
\hline
\end{tabular}

Hausman test and LR test results show that we can build individual fixed model, rather than the mixed model and the individual random model. In addition, by establishing the variable coefficient model, the fixed effects model, and the constant parameter model and set out to do F value test to determine the model forms.

TABLE 4 THE ESTABLISHED THE REGRESSION RESULTS

\begin{tabular}{|l|l|l|l|}
\hline & Fixed effects model & Mixed model & $\begin{array}{l}\text { Variable } \\
\text { coefficient model }\end{array}$ \\
\hline Adjusted R-squared & 0.661292 & 0.5602592 & 0.7002856 \\
\hline sum squared resid & $0.816 \mathrm{E}+08$ & $1.576 \mathrm{E}+08$ & 44077949 \\
\hline prob. & 0.000000 & 0.000000 & 0.000000 \\
\hline
\end{tabular}


Calculated according to the results of the regression, $\mathrm{F} 2=4.26, \mathrm{~F} 1=2.12$, in a given significance level of $5 \% \mathrm{~F} 1$ and F2 are greater than threshold, it refused to $\mathrm{H} 1, \mathrm{H} 2$, respectively, model with variable coefficients form should be adopted.

\section{EMPIRICAL TESTS}

\section{A. Cointegration test results}

We build a fixed effects model with variable coefficients, real estate value and GDP volatility analysis of the relationship between the established model is as the following form:

$\mathbf{G D P i}=\alpha \mathbf{i}+\beta \mathbf{0 i} * \mathbf{C H P i}+\beta \mathbf{1 i} * \mathbf{C H A i}+\mathbf{u i}$

TABLE 5 FIXED EFFECTS MODEL WITH VARIABLE COEFFICIENTS TEST RESULTS

\begin{tabular}{|l|l|l|l|l|l|l|l|}
\hline Area & CHP & CHA & $\alpha$ & Area & CHP & CHA & $\alpha$ \\
\hline Beijing & 3.425801 & -12.96057 & -1475.398 & Hunan & 1.475194 & -0.452977 & 59.3118 \\
\hline Tianjin & 1.721042 & 0.0419584 & -1582.034 & Guangdon & 1.30398 & -8.401952 & 2044.9144 \\
\hline Hebei & 1.252055 & -2.370096 & 581.532 & Guangxi & 0.98971 & 3.034835 & 323.83832 \\
\hline Shanxi & 1.415601 & -0.487002 & 93.5282 & Hainan & 1.26737 & 56.90690 & 26.927352 \\
\hline Neimeng & 1.013662 & 0.9202584 & 105.0168 & Chongqin & 1.016156 & 1.773363 & 176.79104 \\
\hline Liaoning & 1.254636 & 0.3219816 & -30.57433 & Sichuan & 1.2668296 & -3.67248 & 1119.768 \\
\hline Jilin & 1.586791 & 2.8625768 & -1101.624 & Guizhou & 0.9019808 & 4.168124 & -23.72874 \\
\hline Helongji & 2.307593 & 0.2764896 & -1762.639 & Yunan & 0.571505 & -2.905375 & 1622.1712 \\
\hline Jiangsu & 2.559213 & -0.751730 & -1166.221 & Tibet & 1.073432 & -0.148152 & 94.27136 \\
\hline Zhejiang & 2.385383 & -8.500088 & -643.69 & Shanaxi & 1.1963736 & -1.096538 & 559.8606 \\
\hline Anhui & 2.117434 & -3.387744 & -256.7482 & Gansu & 1.841243 & -2.605302 & -133.5020 \\
\hline Fujian & 1.574912 & 3.346908 & 141.6453 & Qinghai & 0.787178 & -7.925726 & 996.5464 \\
\hline Jiangxi & 1.925059 & -0.456723 & -21.4959 & Ningxia & 1.00172 & 0.533197 & 549.2589 \\
\hline Shandon & 1.555313 & 4.461846 & -1996.015 & Xinjiang & 1.008985 & -2.614874 & 832.4544 \\
\hline Henan & 1.140459 & 0.667717 & 293.1594 & Mean & 1.4762226 & 0.6452145 & \\
\hline Hubei & 1.350039 & -0.375428 & 379.5349 & & & & \\
\hline
\end{tabular}

The test result of the model as shown in table 5 , the real estate value nd GDP in 29 provinces are homodromous, e.g. the real estate value has a long-term positive effect on the GDP. With every percentage of the real estate value changed, the GDP increased by 1.4762226 at national level. As for the coefficient, there exists differences among different provinces. Beijing has the highest influence degree whose coefficient is 3.4258144,while Yunnan's influence degree is the lowest and this coefficient is just 0.571506 .As can be seen from the data, the coefficient of the eastern region with mature developed market is larger than the western region.

The area of commercial housing also has effect on the GDP, but the extent of the impact is smaller than the influence of the price. On a purely national level, a $1 \%$ change in the area of commercial housing is associated with a $0.8065181 \%$ increase in GDP. The area of commercial housing has different impacts on the long-term GDP in different places and the impacts can be positive or negative. There are 13 provinces having been influenced positively while 16 provinces have been influenced negatively among 29 provinces. The correlation between the two-way effects and the market development is not obvious .Both the provinces with mature market and the provinces with less-developed one are under the two-sides effects.

\section{$B$. The test result of error correction model}

Due to there is a cointegration relationship between the three variables, then when we next, establish panel error correction model, firstly, gain the residual term using the model of long-term relationship, then establish the dynamic panel error correction model.

Error correction model combined the short-term undulation with long-term equilibrium in a model which reflects free adjustment process of the system when the equilibrium appeared deviating. This paper establishes error correction model based on the panel data(table 6), the model estimates $\mathrm{R} 2=0.89$, $\mathrm{DW}=2.38$ and the equation of fitting performance is good. 
TABLE 6 ERROR CORRECTION MODEL TEST RESULTS

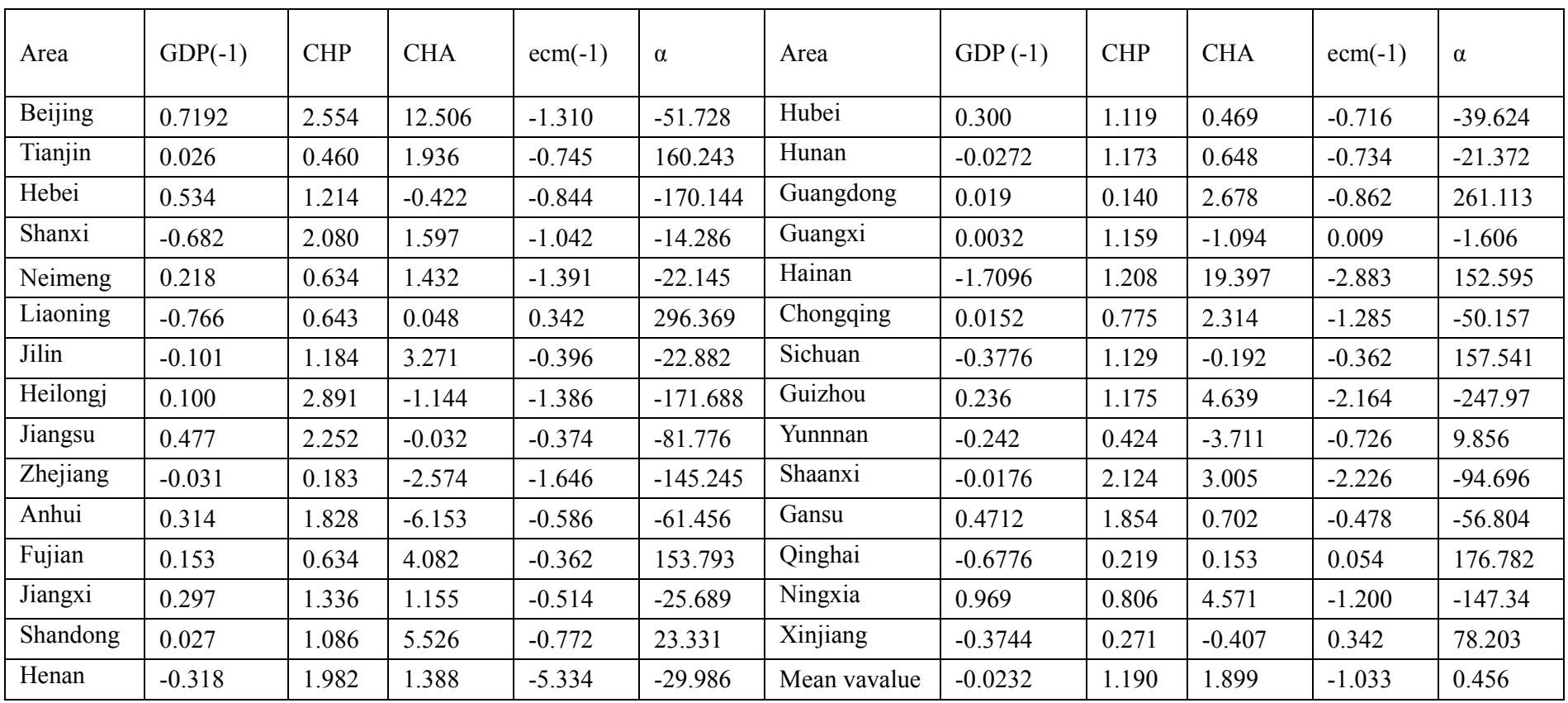

The the real estate value has a positive impact on the GDP and the average elastic coefficient is 1.19069 which is smaller than the long-term one 1.476222 at national level. Additionally, the size of the commercial housing also have positive impact on the GDP and its average coefficient is 1.899227 which is higher than the long-term average elastic coefficient 0.6452145 . This also reflects the influence of the supply of commercial housing in the area is higher than the GDP in the short term.

From the point of the error correction system, the average of error correction coefficient is -1.033784 which shows that when the short-term fluctuations deviated from its long-term equilibrium, and it will be adjust unbalanced state back to equilibrium with -1.033784 .

\section{CONCLUSIONS}

In this paper, we use the panel data from 2002 to 2010 of 29 provinces, municipalities and autonomous regions to test the relationship between the real estate value and GDP, then we have reached the following main conclusions:

From the price point of view, the impact which the housing prices on GDP is positive on the national level, however, the fluence in eastern regions is bigger than in western regions because market is mature in eastern regions.

Judging from the area, the impact which the housing areas on GDP is positive on the national level, however, the influence is different in various of regions since it associates with the degree of the market development. In the short term, the impact on GDP of the area of commercial housing supply is higher than the price, however, in the long term, the impact on GDP of the commercial housing price is higher than the housing supply areas.

$=$ The value of real estate can indeed produce the impact on GDP but there are regional differences, we can not over-exaggerate the real estate value of the impact on GDP, this may have a negative impact.

\section{ACKNOWLEDGEMENTS}

A Project Funded by the Priority Academic Program Development of Jiangsu Higher Education Institutions.

\section{REFERENCES}

[1] Wang Xianzhu. Impact of Affordable Housing on Housing Price. [J]. The economic system reform,2009(5)

[2] Chen Youyi . Affordable Housing Policies on the Real Estate Market and Its Price Impact Analysis.[J]. Price Theory and Practice,2009(4)

[3] Pan Aimin ,Han Zzhenglong. Affordable Housing, Land Prices and Housing Prices[J]. Journal of yanbian university,2012(1)

$[4]$

Fratantoni M,Schuh S.Monetary policy,Housing and Heterogeneou s Regional Markets.Journal of Money,Credit and Bangking,2003(3 5)

[5] Damodar N.Gujarrti.Essentials of Econometries(3rd Edition)[M].Beijing:China Machine Press,2006 